\title{
Erratum to: Glucose, blood pressure and cholesterol levels and their relationships to clinical outcomes in type 2 diabetes: a retrospective cohort study
}

Evangelos Kontopantelis • David A. Springate •

David Reeves • Darren M. Ashcroft • Martin K. Rutter • Iain Buchan • Tim Doran

Published online: 20 February 2015

(C) Springer-Verlag Berlin Heidelberg 2015

\section{Erratum to: Diabetologia}

\section{DOI 10.1007/s00125-014-3473-8}

Unfortunately, Dr Rutter's middle initial was omitted from the original author list. His name appears correctly in this erratum.

The online version of the original article can be found at http://dx.doi.org/ 10.1007/s00125-014-3473-8.

E. Kontopantelis $\cdot$ D. A. Springate $\cdot$ D. Reeves

NIHR School for Primary Care Research, Centre for Primary Care, Institute of Population Health, University of Manchester,

Manchester, UK

E. Kontopantelis $(\bowtie) \cdot \mathrm{I}$. Buchan

Centre for Health Informatics, Institute of Population Health,

University of Manchester, Vaughan House, Portsmouth Street,

Manchester M13 9GB, UK

e-mail: e.kontopantelis@manchester.ac.uk

D. A. Springate $\cdot$ D. Reeves

Centre for Biostatistics, Institute of Population Health, University of

Manchester, Manchester, UK

D. M. Ashcroft

Centre for Pharmacoepidemiology and Drug Safety Research,

Manchester Pharmacy School, University of Manchester,

Manchester, UK
M. K. Rutter

Endocrinology and Diabetes Research Group, Institute of Human Development, Faculty of Medical and Human Sciences, University of Manchester, Manchester, UK

M. K. Rutter

Manchester Diabetes Centre, Central Manchester University Hospitals NHS Foundation Trust, Manchester Academic Health Science Centre, Manchester, UK

T. Doran

Department of Health Sciences, University of York, York, UK 